\title{
Levantamento fitossociológico de plantas daninhas em cultivo de couve-folha em consorciação com quiabeiro em sistema de produção orgânico
}

Phytosociological survey of weeds in cultivation of leaf cabbage intercropped with okra in an

organic production system

Estudio fitosociológico de malezas en el cultivo de repollo intercalado con okra en un sistema de producción orgánica

Recebido: 18/01/2021 | Revisado: 23/01/2021 | Aceito: 27/01/2021 | Publicado: 02/02/2021

\author{
Guilherme Augusto Boes Sackser \\ ORCID: https://orcid.org/0000-0003-0371-1804 \\ Universidade Estadual do Oeste do Paraná, Brasil \\ E-mail: guilhermesackser@hotmail.com \\ Jaqueline de Araújo Barbosa \\ ORCID: https://orcid.org/0000-0002-8954-5204 \\ Universidade Estadual do Oeste do Paraná, Brasil \\ E-mail: jaquelineabarbosa@hotmail.com \\ Márcia de Moraes Echer \\ ORCID: https://orcid.org/0000-0003-4691-4273 \\ Universidade Estadual do Oeste do Paraná, Brasil \\ E-mail: marcia.echer@unioeste.br \\ Thatiane Nepomuceno Alves \\ ORCID: https://orcid.org/0000-0002-9077-9104 \\ Universidade Estadual Paulista 'Júlio de Mesquita Filho', Brasil \\ E-mail: thatianepomuceno@hotmail.com
}

\begin{abstract}
Resumo
O objetivo deste trabalho foi realizar o levantamento fitossociológico de plantas daninhas no cultivo de couve-folha em consorciação com o quiabeiro. O experimento foi conduzido em blocos casualizados, com quatro repetições. Os tratamentos foram constituídos pelos seguintes arranjos: T1 (três linhas de couve com quiabeiro nas entrelinhas), T2 (três linhas de couve com quiabeiro a cada duas entrelinhas), T3 (três linhas de couve com quiabeiro adensado nas entrelinhas), T4 (três linhas de couve com quiabeiro adensado a cada duas entrelinhas), T5 (couve), T6 (quiabeiro), T7 (quiabeiro adensado) e T8 (palhada de aveia). Aos 17 dias após o transplante (DAT) e em intervalos quinzenais até 152 DAT foram realizadas amostragens com quadro de $0,09 \mathrm{~m} 2$, aleatoriamente em cada parcela. As plantas daninhas foram quantificadas e identificadas estabelecendo-se o número total de indivíduos e a densidade total de plantas por $\mathrm{m}^{2}$. Ao final de 77 e 152 DAT estabeleceu-se a frequência absoluta, frequência relativa, densidade absoluta, densidade relativa, abundância absoluta, abundância relativa e o índice de valor de importância das espécies mais representativas. Identificou-se 23 espécies distribuídas em 14 famílias, destacando a família Asteraceae, com 5 espécies. As espécies mais importantes foram Sonchus oleraceus e Richardia brasilenses, presentes em no mínimo 5 dos 8 tratamentos. O consórcio T1, teve redução de 38\% no número de indivíduos e de 37,9\% na densidade de plantas por $\mathrm{m}^{2}$ em relação ao cultivo de couve-folha solteiro. O consórcio de couve-folha com quiabeiro reduz a infestação de plantas daninhas e pode ser explorado como alternativa de manejo.
\end{abstract}

Palavras-chave: Manejo; Brassica oleracea; Abelmoschus esculentus.

\begin{abstract}
The objective of this work was to carry out a phytosociological survey of weeds in the cultivation of cabbage in consortium with okra. The experiment was carried out in random blocks, with four replications. The treatments consisted of the following arrangements: T1 (three lines of cabbage with okra between the lines), T2 (three lines of cabbage with okra every two lines), T3 (three lines of cabbage with dense okra between the lines), T4 (three lines of cabbage with thick okra every two rows), T5 (cabbage), T6 (okra), T7 (thick okra) and T8 (oat straw). At 17 days after transplantation (DAT) and at fortnightly intervals up to 152 DAT, samples with $0.09 \mathrm{~m} 2$ were taken, randomly in each plot. Weeds were quantified and identified by establishing the total number of individuals and the total plant density per $\mathrm{m}^{2}$. At the end of 77 and 152 DAT, absolute frequency, relative frequency, absolute density, relative density, absolute abundance, relative abundance and the importance value index of the most representative species were established. It was identified 23 species distributed in 14 families, highlighting the Asteraceae family, with 5 species. The most important species were Sonchus oleraceus and Richardia brasilenses, present in at least 5 of the 8 treatments. The T1 consortium had a reduction of $38 \%$ in the number of individuals and $37.9 \%$ in the density of plants
\end{abstract}


per $\mathrm{m}^{2}$ in relation to the cultivation of single cabbage. The consortium of cabbage with okra reduces weed infestation and can be explored as a management alternative.

Keywords: Management; Brassica oleracea; Abelmoschus esculentus.

\section{Resumen}

El objetivo de este trabajo fue realizar un relevamiento fitosociológico de malezas en el cultivo de col de hoja en consorcio con okra. El experimento se realizó en bloques al azar, con cuatro repeticiones. Los tratamientos consistieron en los siguientes arreglos: T1 (tres líneas de repollo con okra entre las líneas), T2 (tres líneas de repollo con okra en cada dos líneas), T3 (tres líneas de repollo con okra denso entre las líneas), T4 (tres líneas de repollo con okra espeso cada dos líneas), T5 (repollo), T6 (okra), T7 (okra espeso) y T8 (paja de avena). A los 17 días posteriores al trasplante (DAT) y a intervalos quincenales hasta 152 DAT, se tomaron muestras con $0.09 \mathrm{~m} 2$, al azar en cada parcela. Las malezas se cuantificaron e identificaron estableciendo el número total de individuos y la densidad total de plantas por $\mathrm{m}^{2}$. Al final de 77 y 152 DAT se estableció la frecuencia absoluta, frecuencia relativa, densidad absoluta, densidad relativa, abundancia absoluta, abundancia relativa y el índice de valor de importancia de las especies más representativas. Se identificaron 23 especies distribuidas en 14 familias, destacando la familia Asteraceae, con 5 especies. Las especies más importantes fueron Sonchus oleraceus y Richardia brasilenses, presentes en al menos 5 de los 8 tratamientos. El consorcio T1 tuvo una reducción del 38\% en el número de individuos y del 37,9\% en la densidad de plantas por $\mathrm{m}^{2}$ en relación al cultivo de col simple. El consorcio de repollo con okra reduce la infestación de malezas y puede explorarse como una alternativa de manejo.

Palabras clave: Manejo; Brassica oleracea; Abelmoschus esculentus.

\section{Introdução}

As culturas de couve-folha (Brassica oleracea) e do quiabeiro (Abelmoschus esculentus L, Moech), são com frequência cultivadas em monocultivo. Estas apresentam crescimento inicial lento e ao serem cultivadas em largos espaçamentos, favorecem a emergência e o desenvolvimento de plantas daninhas, diante da menor cobertura do solo (Rezende et al., 2009).

As espécies de plantas daninhas competem com a cultura de interesse por recursos essenciais ao desenvolvimento das plantas, como nutrientes, espaço e luminosidade. Na ausência de controle da comunidade infestante, o comprometimento do potencial produtivo de hortaliças como o quiabeiro atinge em cerca de 85\% (Fukushi et al., 2011; Uljol et al., 2018).

Técnicas envolvendo o manejo cultural como o adensamento ou consórcio entre culturas, permite o fechamento rápido da entrelinha e desfavorece a emergência de plantas daninhas (Olsen et al., 2012; D’amico-damião et al., 2020). Assim, a consorciação contribui para o melhor aproveitamento do solo, favorece o equilíbrio ecológico, e auxilia no manejo de plantas daninhas (Alves et al., 2020; Koefender et al., 2016).

Há relatos quanto a consorciação de quiabeiro, alface e rabanete, com redução de $30 \%$ de comunidade de plantas daninhas (Fukushi et al., 2011), e de couve-folha com cariru, com 15\% de aumento na eficiência produtiva em relação aos cultivos solteiros e controle de plantas daninhas (Cardoso et al., 2017). Mas escassos são os relatos quanto a consorciação entre a cultura da couve-folha e a cultura do quiabeiro.

A supressão de espécies infestantes com a consorciação de culturas pode reduzir medidas de manejo a serem implementadas, como a necessidade de capinas regulares (Rezende et al., 2009).

Entre os métodos mais utilizados no reconhecimento da comunidade de plantas daninhas, principalmente em áreas de produção agrícola, está o estudo fitossociológico, o qual irá determinar quais espécies apresentam maior importância na estrutura da comunidade infestante, e que devem ser priorizadas na implementação de estratégias de manejo (Oliveira et al., 2014).

Desta forma, este trabalho teve como objetivo avaliar o efeito do consórcio entre as culturas de couve-folha (Brassica oleracea) e do quiabeiro (Abelmoschus esculentus L, Moech), na comunidade de plantas daninhas em área de cultivo. 


\section{Metodologia}

O experimento foi realizado entre maio de 2017 a janeiro de 2018, no setor de horticultura orgânica localizado nas coordenadas 33' 22' S; 540 31' 24' W; $420 \mathrm{~m}$ de altitude. O solo da região constitui-se de LATOSSOLO VERMELHO eutroférrico (LVef), (Santos, 2018), e o clima se enquadra no tipo Cfa, segundo a classificação de Koppen.

Os dados da temperatura, umidade relativa do ar, radiação e precipitação referentes ao período do experimento foram obtidos na Estação Meteorológica de Observação de Superfície Automática de Marechal Candido Rondon (Figura 1).

Figura 1. Temperatura média do ar e precipitação pluviométrica referente ao período de condução das culturas. Unioeste Marechal Cândido Rondon, setembro 2017 a março 2018.

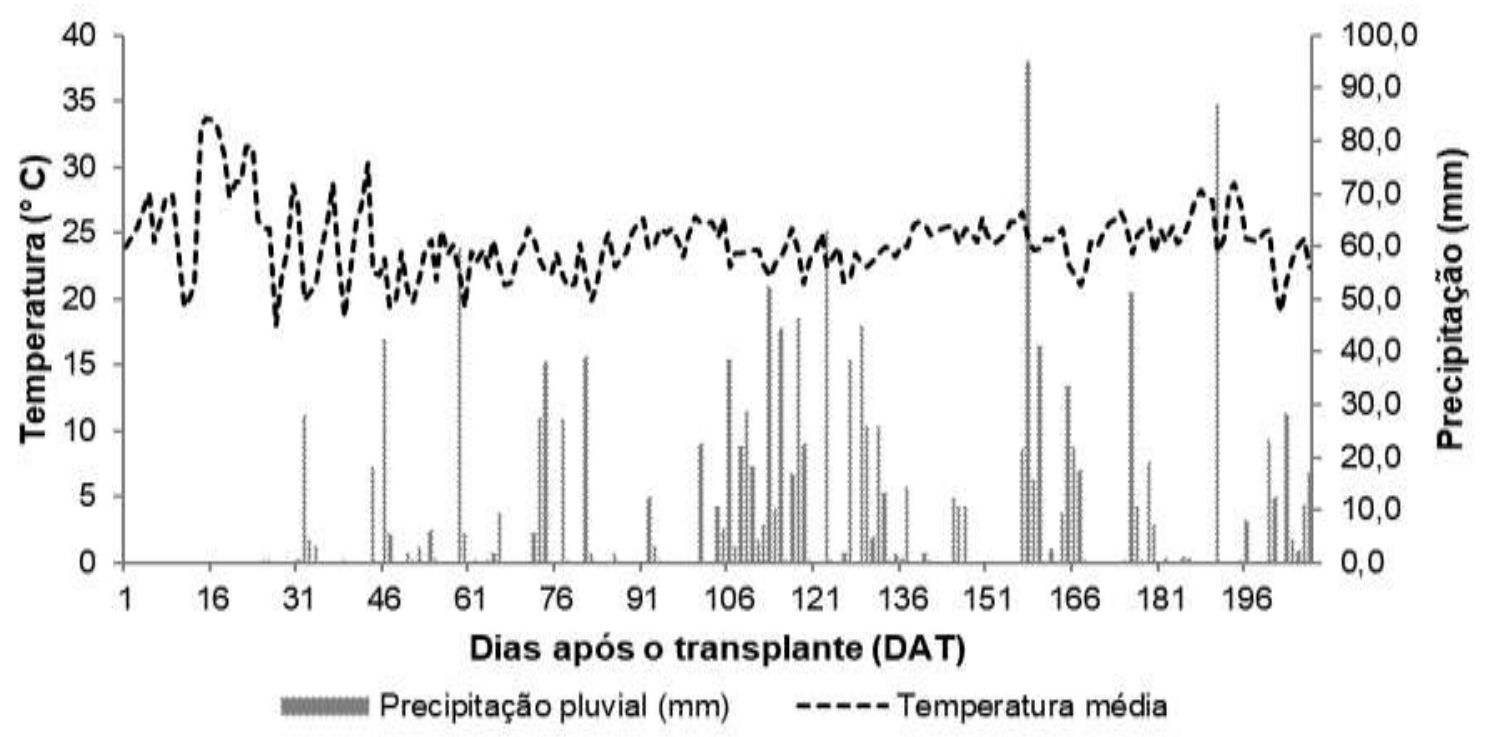

Fonte: Autores.

Previamente a instalação do experimento, foi realizado cultivo da aveia (Avena sativa). O solo foi preparado mecanicamente por aração e gradagem e nesta ocasião também foi realizada a calagem e aplicado 4,6 kg m-2 de composto orgânico. A semeadura da aveia obedeceu ao espaçamento de $0,20 \mathrm{~m}$ entre linhas, e entre plantas de $0,05 \mathrm{~m}$.

As plantas foram roçadas rente ao solo ao final do ciclo vegetativo e a biomassa total seca da área determinada com quadro de $0,25 \mathrm{~m} 2(0,5 \times 0,5 \mathrm{~m})$, lançados 10 vezes ao acaso. $\mathrm{O}$ material coletado foi submetido a secagem em estufa de circulação forçada de ar $\left(65^{\circ} \mathrm{C}\right)$ até atingir massa seca constante, obtendo-se uma massa seca média de palhada de aproximadamente $3,83 \mathrm{t}$ ha- 1 .

A análise química do solo após o manejo da aveia apresentou os seguintes atributos químicos: $\mathrm{pH}(\mathrm{CaCl} 2)=5,33$; $\mathrm{MO}=21,87 \mathrm{~g} \mathrm{dm}-3 ; \mathrm{P}=195,78 \mathrm{mg} \mathrm{dm}-3 ; \mathrm{Mg}+2$ 3,05 cmolc dm-3; K= 1,37 cmolc dm-3; Ca 2+ =11,25 cmolc dm-3; $\mathrm{Al}+=0,00$ cmolc dm-3; $\mathrm{SB}=15,67 \mathrm{cmolc} \mathrm{dm}-3 ; \mathrm{CTC}=19,75 \mathrm{cmolc} \mathrm{dm}-3 ; \mathrm{H}+\mathrm{Al}=4,08 \mathrm{cmolc} \mathrm{dm}-3 \mathrm{e} \mathrm{V}=79,34 \%$.

As mudas de couve manteiga da cultivar "Geórgia" e do quiabeiro "Santa Cruz" foram produzidas em bandejas de polietileno de 200 células, contendo substrato orgânico. Estas foram mantidas suspensas sobre bancadas em casa de vegetação até o momento do transplante, que ocorreu ao sexto dia de setembro de 2017. As culturas foram implantadas simultaneamente sobre soba palhada da aveia, em sistema de cultivo orgânico.

O delineamento experimental utilizado foi de blocos casualizados, com quatro repetições e oito tratamentos, sendo eles: T1 (três linhas de couve com quiabeiro nas entrelinhas), T2 (três linhas de couve com quiabeiro a cada duas entrelinhas), T3 (três linhas de couve com quiabeiro adensado nas entrelinhas), T4 (três linhas de couve com quiabeiro adensado a cada 
duas entrelinhas), T5 (couve em monocultivo), T6 (quiabeiro em monocultivo), T7 (quiabeiro em mono cultivo adensado) e T8 (palhada de aveia).

Nos monocultivos, a couve e quiabeiro foram implantados em espaçamento de $1,20 \times 0,50 \mathrm{~m}$ entrelinhas e entre plantas, respectivamente. Para o quiabeiro adensado adotou-se o espaçamento entre plantas de 0,25 m. Nos consórcios, as linhas de plantio estavam afastadas entre si a uma distância de $0,60 \mathrm{~m}$.

Cada parcela experimental possuía uma dimensão de 7,00 m de comprimento x 3,60 m de largura, totalizando 25,2 m2. A adubação da cultura foi realizada tomando como base a análise de solo, e as recomendações de Trani et al. (2013) e Souza et al. (2008), sendo aplicado $4,6 \mathrm{~kg} \mathrm{~m}^{2}$ de composto orgânico para adubação.

A irrigação na área experimental durante o experimento foi realizada por aspersão, conforme a necessidade da cultura, de forma que a falta de água não fosse um fator de influência.

A caracterização e o estudo fitossociológico da comunidade de plantas daninhas foi realizada aos 17 dias após o transplante e em seguida, em intervalos quinzenais até o final de 152 dias. As amostragens foram efetuadas arremessando-se, aleatoriamente, uma moldura de 0,09 $\mathrm{m} 2(0,3 \times 0,3 \mathrm{~m})$, sendo realizada uma repetição por parcela, seguindo metodologia proposta por Oliveira \& Freitas (2008). Posteriormente, as plantas daninhas emergidas foram contabilizadas e identificadas de acordo com literatura (Lorenzi, 2006).

Em cada avaliação quinzenal, as plantas daninhas foram quantificadas e identificadas, a fim de se estabelecer o número total de indivíduos e a densidade total de plantas $\mathrm{m}^{2}$ durante todo o período de cultivo.

Ao final de 77 e 152 DAT estabeleceu-se a frequência absoluta (F), frequência relativa (FR), densidade absoluta (D), densidade relativa (DR), abundância absoluta (A), abundância relativa (AR) e o índice de valor de importância (IVI) das espécies mais representativas, baseados na metodologia proposta por Mueller-Dombois e Ellenberg (1974).

\section{Resultados e Discussão}

O levantamento fitossociológico da comunidade infestante apresentou a ocorrência de 23 espécies de plantas daninhas em toda a área de cultivo, distribuídas em 14 famílias, que estão representadas na Tabela 1. As principais famílias foram Asteraceae, com 5 espécies e Amaranthaceae e Poaceae, com 3 espécies cada. 
Tabela 1. Família, espécie e nome comum da comunidade de plantas daninhas identificada na área de cultivo de couve-folha consorciado com quiabeiro.

\begin{tabular}{|c|c|}
\hline Família & Nome científico \\
\hline \multirow{5}{*}{ Asteraceae } & Achyrocline satureioides \\
\hline & Ageratum conyzoides $L$. \\
\hline & Sonchus oleraceus \\
\hline & Bidens pilosa $L$. \\
\hline & Conyza bonariensis \\
\hline \multirow{3}{*}{ Amaranthaceae } & Amaranthus deflexus \\
\hline & Amaranthus viridis \\
\hline & Spinacia oleracea \\
\hline Apiaceae & Apium leptophyllum \\
\hline \multirow{2}{*}{ Euphorbiaceae } & Phyllanthus corcovadensis \\
\hline & Chamaesyce hirta \\
\hline \multirow[t]{2}{*}{ Commelinaceae } & Commelina benghalensis $L$. \\
\hline & Lolium multiflorum Lam. \\
\hline \multirow[t]{2}{*}{ Poaceae } & Cynodon dactylon \\
\hline & Eleusine indica \\
\hline Cyperaceae & Cyperus rotundus L. \\
\hline Plantaginaceae & Plantago lanceolata \\
\hline Lamiaceae & Leonurus sibiricus \\
\hline Brassicaceae & Raphanus raphanistrum \\
\hline Rubiaceae & Richardia brasiliensis \\
\hline Malvaceae & Sida glaziovii \\
\hline Solanaceae & Solanum americanum \\
\hline Fabaceae & Trifolium \\
\hline
\end{tabular}

Fonte: Autores.

As famílias identificadas em maior ocorrência neste trabalho também são comuns em outras regiões agrícolas (Canuto et al., 2020; Almeida et al., 2019; Silva, et al., 2018; Soares et al., 2015; Santos et al., 2015).

No cultivo do mamão, por exemplo, Costa et al. (2019) determinaram que a família Poaceae representou $27 \%$ do total das espécies identificadas, seguida pela família Asteraceae, com 19\%, e Amaranthaceae com 8\%. Em área de cultivo de sorgo granífero, Custódio et al. (2019) determinaram que 39\% das espécies encontradas pertenciam à família Poaceae, e 22\% à Asteraceae.

Neste trabalho, a família Asteraceae compôs 21\% das espécies identificadas, e junto com as famílias Poaceae (13\%) e Amaranthaceae (13\%), somam 47\% do total das espécies identificadas em toda a área cultivada. A alta incidência de espécies das famílias identificadas, são explicadas, em parte, pela grande quantidade de produção de diásporos, que facilitam sua disseminação em variados ambientes (Lorenzi, 2008; Maciel et al., 2010).

Além disso, espécies de Amaranthaceae e Poaceae são plantas de metabolismo fotossintético C4, e a maior ocorrência dessas espécies pode estar relacionada a capacidade destas espécies em acumulando maior quantidade de matéria seca quando comparada com plantas C3, se tornando mais competitivas em cultivos de plena luminosidade (Meirong et al., 1996; Oliveira 
\& Freitas, 2008; Fank-de-Carvalho et al., 2010).

O consórcio entre as plantas de couve-folha e quiabeiro interferiram na emergência das plantas daninhas durante todo o ciclo de cultivo. Conforme apresentado na Figura 2A e 2B, aos 17 dias após o transplante (DAT) das mudas, observou-se que os cultivos solteiros apresentaram maior número de plantas e maior densidade de plantas daninhas por $\mathrm{m}^{2}$, em relação aos cultivos consorciados de couve-folha e quiabeiro.

Aos 17 DAT, as parcelas cultivadas em sistema de couve-folha solteiro apresentaram o maior número de plantas (61 plantas), e a maior densidade total de plantas daninhas por $\mathrm{m}^{2}$ (169 plantas $\mathrm{m}^{2}$ ). Em seguida, o cultivo de quiabeiro em sistema solteiro adensado, que apresentou 34 plantas e densidade de 94 plantas $\mathrm{m}^{2}$; seguido pelo cultivo de quiabeiro solteiro, com 30 plantas e densidade de 83 plantas $\mathrm{m}^{2}$. As parcelas que corresponderam apenas ao cultivo da palhada (T8), livre de culturas, apresentou o número de 28 plantas daninhas e densidade de 77 plantas $\mathrm{m}^{2}$ aos 7 DAT.

A consorciação das culturas demonstrou menor número de plantas e menor densidade de plantas por $\mathrm{m}^{2}$. Em especial, a consorciação de couve-folha com quiabeiro adensado a cada 2 entrelinhas (T4), que aos 17 DAT apresentou 16 plantas, e densidade de 44 plantas por $\mathrm{m}^{2}$. Em comparação ao cultivo de couve-folha em sistema de cultivo solteiro (T5), o número de plantas foi menor em $73,8 \%$ e a densidade de plantas por $\mathrm{m}^{2}$ foi menor em $74,9 \%$.

Figura 2. Número (A) e densidade total (B) de plantas daninhas, na área de cultivo com couve-folha e quiabeiro em consórcio e solteiro.
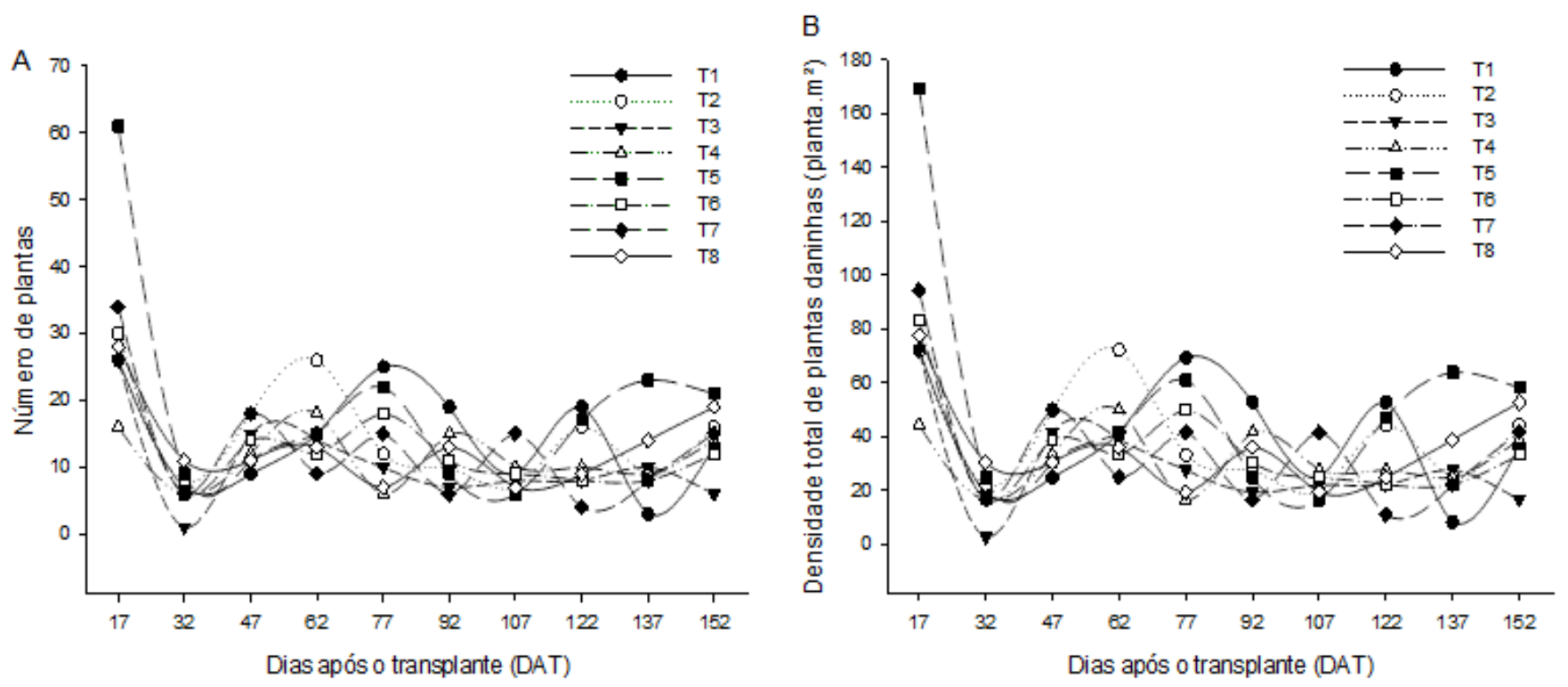

T1 (três linhas de couve com quiabeiro nas entrelinhas), T2 (três linhas de couve com quiabeiro a cada duas entrelinhas), T3 (três linhas de couve com quiabeiro adensado nas entrelinhas), T4 (três linhas de couve com quiabeiro adensado a cada duas entrelinhas), T5 (couve em monocultivo), T6 (quiabeiro em monocultivo), T7 (quiabeiro em mono cultivo adensado) e T8 (palhada de aveia). Fonte: Autores.

Os demais cultivos consorciados apresentaram número de plantas e densidade de plantas $\mathrm{m}^{2}$ inferior em média de 57,4\% em relação ao cultivo de couve-folha em sistema solteiro. Plantios mais densos e consorciados dificultam o desenvolvimento das plantas daninhas, pois a inserção de mais de uma espécie intensifica a competição intra e interespecífica por recursos como água, nutrientes, e principalmente a luminosidade (Fukushi el al., 2011; Machado et al., 2011).

O sistema de consorciação de couve-folha com o quiabeiro, aliada ao adensamento, promove o abafamento da região da entrelinha, reduz a interceptação de luminosidade, e com isso, limita a emergência e o crescimento pleno de algumas espécies de plantas daninhas (Moreira et al., 2013; Costa et al., 2018). 
Ao longo do ciclo de cultivo, observa-se oscilação no número de plantas e na densidade de plantas daninhas por m². Isto ocorre, pois a comunidade de plantas daninhas sofre alterações ao logo do ciclo de desenvolvimento, com espécies de ciclo curto ou longo, mais competitivas e menos competitivas. Além disso, conforme ocorre o crescimento das culturas, as novas espécies de plantas daninhas que emergem já não conseguem se desenvolver de forma adequada devido ao abafamento e redução da luminosidade imposta pelas culturas.

Ao final do ciclo, aos 152 DAT, além da redução observada quando comparada a avaliação aos 17 DAT, observa-se, novamente, que os cultivos em sistema solteiros apresentaram maior número de plantas e maior densidade de plantas daninhas por $\mathrm{m}^{2}$, devido a maior proporção de área descoberta, enquanto os sistemas consorciados proporcionaram maior cobertura do solo (Almeida et al., 2019).

O cultivo de couve-folha solteiro (T5) apresentou aos 152 DAT o maior número de plantas (21 plantas) e a maior densidade de plantas por $\mathrm{m}^{2}\left(58\right.$ plantas $\mathrm{m}^{2}$ ), seguido pelo cultivo apenas com a palhada (T8), com 19 plantas e densidade de 52 plantas $\mathrm{m}^{2}$.

A maior quantidade de plantas e a maior densidade de plantas daninhas na área com a palhada (T8) pode ser justificada pela decomposição da palhada. Aos 152 DAT, a ausência da palhada em função da sua decomposição, favoreceu a emergência de plantas daninhas, já que não havia mais o impedimento físico e barreiras na passagem de luminosidade para o pleno desenvolvimento de plantas daninhas.

No ambiente de cultivo, ao momento de decomposição da palhada, a cultura já se encontra estabelecida, à exemplo dos sistemas consorciados avaliados neste trabalho. O cultivo consorciado de couve-folha com quiabeiro a cada 2 entrelinhas (T2), apresentou 16 plantas e densidade de 44 plantas $\mathrm{m}^{2}$, menor em $23,8 \%$ e 24,1\%, respectivamente, em relação ao cultivo de couve-solteiro.

Quando realizado o cultivo consorciado de couve-folha e quiabeiro em cada entrelinha (T1), o número de plantas foi menor em $38 \%$, e a densidade de plantas $\mathrm{m}^{2}$ menor em $37,9 \%$ em relação ao cultivo de couve-folha solteiro. A redução foi ainda maior no cultivo consorciado de couve-folha com quiabeiro adensado a cada entrelinha (T3), que chegou a ser menor em $71,4 \%$ no número de plantas e na densidade de plantas por $\mathrm{m}^{2}$ em relação ao cultivo de couve-folha solteiro (T5), sendo este a menor densidade observada em relação aos demais cultivos consorciados.

O sistema de consorciação em plantio direto permite inúmeros benefícios, pois além de permitir a supressão da comunidade de plantas daninhas, permite a manutenção umidade e menor oscilação da temperatura do solo devido a maior cobertura do solo (Ziech et al., 2015; Albuquerque et al., 2012).

Ao se estabelecer as espécies com maior incidência na área de cultivo aos 77 e 152 DAT, observou-se predominância das espécies Eleusine indica, Sonchus oleraceus, Richardia brasiliensis, Cynodon dactylon, Commelina benghalensis, Chamaesyce hirta, Phyllanthus niruri, Lolium temulentum e Ageratum conyzoides, conforme apresentado nas Tabelas 2 e 3.

Àquelas espécies mais importantes em termos de infestação em cada modelo de cultivo, são as que apresentam maior índice de valor de importância (IVI), conforme descreve Pitelli (2000). Neste trabalho, nas parcelas em que houve a predominância de até 3 espécies, as espécies mais importantes foram S. oleraceus e R. brasiliensis aos 77 DAT, e S. oleraceus, C. hirta e $R$. brasiliensis aos 152 DAT.

Aos 77 DAT, a espécie $S$. oleraceus foi identificada em 7 dos 8 sistemas de cultivo, com maior índice de importância (IVI) no cultivo de couve-folha e quiabeiro na entrelinha (T1), e correspondeu a $84 \%$ da densidade de todas as espécies. A menor densidade dessa espécie foi observada no cultivo de palha de aveia (T8), e correspondeu apenas a $14 \%$ da densidade total de plantas daninhas. Na condição de apenas palhada, houve maior incidência de diferentes espécies (Tabela 2). 
Tabela 2. Parâmetros fitossociológicos obtidos aos 77 DAT das plantas daninhas mais importantes nos sistemas de cultivo.

\begin{tabular}{|c|c|c|c|c|c|c|c|c|}
\hline Tratamentos & Espécies & $\mathrm{F}$ & Fr & $\mathrm{D}$ & $\mathrm{Dr}$ & A & $\mathrm{Ar}$ & IVI \\
\hline \multirow{3}{*}{$\mathrm{T} 1$} & E. indica & 0.25 & 16.67 & 5.56 & 8.00 & 2.00 & 18.18 & 42.85 \\
\hline & S. oleraceus & 0.75 & 50.00 & 58.33 & 84.00 & 7.00 & 63.64 & 197.64 \\
\hline & outras & 0.50 & 33.33 & 5.56 & 8.00 & 2.00 & 18.18 & 59.52 \\
\hline \multirow{3}{*}{$\mathrm{T} 2$} & R.brasiliensis & 0.50 & 25.00 & 5.56 & 16.67 & 1.00 & 14.29 & 55.95 \\
\hline & S. oleraceus & 0.75 & 37.50 & 16.67 & 50.00 & 2.00 & 28.57 & 116.07 \\
\hline & outras & 0.75 & 37.50 & 11.11 & 33.33 & 4.00 & 57.14 & 127.98 \\
\hline \multirow{3}{*}{$\mathrm{T} 3$} & R. brasiliensis & 0.25 & 20.00 & 11.11 & 40.00 & 4.00 & 60.00 & 120.00 \\
\hline & C. dactylon & 0.25 & 20.00 & 2.78 & 10.00 & 1.00 & 15.00 & 45.00 \\
\hline & S. oleraceus & 0.75 & 60.00 & 13.89 & 50.00 & 1.67 & 25.00 & 135.00 \\
\hline \multirow{3}{*}{$\mathrm{T} 4$} & R.brasiliensis & 0.25 & 25.00 & 8.33 & 50.00 & 3.00 & 50.00 & 125.00 \\
\hline & S. oleraceus & 0.25 & 25.00 & 2.78 & 16.67 & 1.00 & 16.67 & 58.33 \\
\hline & outras & 0.50 & 50.00 & 5.56 & 33.33 & 2.00 & 33.33 & 116.67 \\
\hline \multirow[t]{3}{*}{ T5 } & R.brasiliensis & 0.75 & 33.33 & 19.44 & 31.82 & 2.33 & 25.00 & 90.15 \\
\hline & Commelina & 0.50 & 22.22 & 22.22 & 36.36 & 4.00 & 42.86 & 101.44 \\
\hline & outras & 1.00 & 44.44 & 19.44 & 31.82 & 3.00 & 32.14 & 108.41 \\
\hline \multirow[t]{3}{*}{ T6 } & E. indica & 0.25 & 11.11 & 5.56 & 11.11 & 2.00 & 25.00 & 47.22 \\
\hline & S. oleraceus & 1.00 & 44.44 & 33.33 & 66.67 & 3.00 & 37.50 & 148.61 \\
\hline & outras & 1.00 & 44.44 & 11.11 & 22.22 & 3.00 & 37.50 & 104.17 \\
\hline \multirow{3}{*}{$\mathrm{T} 7$} & R.brasiliensis & 0.50 & 25.00 & 11.11 & 26.67 & 2.00 & 26.09 & 77.75 \\
\hline & S. oleraceus & 0.75 & 37.50 & 22.22 & 53.33 & 2.67 & 34.78 & 125.62 \\
\hline & outras & 0.75 & 37.50 & 8.33 & 20.00 & 3.00 & 39.13 & 96.63 \\
\hline \multirow{3}{*}{$\mathrm{T} 8$} & R.brasiliensis & 0.75 & 50.00 & 11.11 & 57.14 & 1.33 & 30.77 & 137.91 \\
\hline & S. oleraceus & 0.25 & 16.67 & 2.78 & 14.29 & 1.00 & 23.08 & 54.03 \\
\hline & outras & 1.25 & 83.33 & 16.67 & 85.71 & 3.33 & 76.92 & 245.97 \\
\hline
\end{tabular}

F - Frequência; Fr - Frequência relativa; D - Densidade; Dr - Densidade relativa; A - Abundância; A - Abundância relativa; IVI - índice de valor de importância.

$\mathrm{T} 1=$ três linhas de couve com quiabeiro nas entrelinhas), T2 = três linhas de couve com quiabeiro a cada duas entrelinhas, T3 = três linhas de couve com quiabeiro adensado nas entrelinhas), T4 (três linhas de couve com quiabeiro adensado a cada duas entrelinhas), T5 (couve em monocultivo), T6 (quiabeiro em monocultivo), T7 (quiabeiro em mono cultivo adensado) e T8 (palhada de aveia).

Fonte: Autores.

A espécie $S$. oleraceus se reproduz por sementes que são facilmente carregadas pelo vento, e tem a capacidade de maturação após o desligamento da planta-mãe sem atingir, necessariamente, a maturação. Desta forma, o não conhecimento desta espécie leva o agricultor a controlar as plantas em estádio final de florescimento ou início de frutificação e ainda ter problemas com essa espécie durante o ciclo (Gazziero et al., 2015; Carvalho et al., 2013).

Aos 77 DAT, a área cultivada com couve-folha e quiabeiro adensado na entrelinha (T3), já apresentava a predominância de 3 espécies, diferente dos outros sistemas de cultivo. Aos 152 DAT, 4 sistemas de cultivos consorciados já apresentavam predominância de apenas 3 espécies, sendo eles, o cultivo de couve-folha com quiabeiro na entrelinha (T1), o cultivo de couve-folha e quiabeiro adensado na entrelinha (T3), o cultivo de couve-folha e quiabeiro adensado a cada 2 entrelinha (T4), e o cultivo de quiabeiro solteiro adensado (T7).

Conforme observado nos resultados, para os cultivos consorciados houve predominância na redução na diversidade de 
espécies em relação aos sistemas de monocultivo, resultados que corroboram com Oliveira et al. (2014). Com a menor diversidade de espécies no ambiente de cultivo, pode-se estabelecer estratégias de manejo mais específicas, como por exemplo, a possibilidade de utilizar a atividade alelopática como alternativa de controle (Rosa et al., 2011).

A alelopatia representa um mecanismo pelo qual determinadas plantas interferem no desenvolvimento de outras, alterando seu padrão e densidade (Smith, 1989). O controle de B. pilosa, E. heterophylla, entre outras espécies são descritos com resultados satisfatórios na literatura (Barbosa et al., 2018; Bernardes et al., 2020; Paula et al., 2020). A campo, há relatos de redução de 59\% na densidade populacional de plantas daninhas através de estratégias alelopáticas (Arif et al., 2015).

Neste trabalho, a espécie $R$. brasiliensis estava presente em 5 dos 8 sistemas de cultivo aos 77 DAT, e apresentou maior IVI na área cultivada com a palhada de aveia, o que correspondeu a 57,14\% da densidade total de plantas daninhas. Aos 152 DAT, novamente as espécies $S$. oleraceus e $R$. brasiliensis predominaram na área de cultivo, estando presentes em 5 dos 8 sistemas de cultivo (Tabela 3).

Tabela 3. Parâmetros fitossociológicos obtidos aos 152 DAT das plantas daninhas mais importantes nos sistemas de cultivo.

\begin{tabular}{|c|c|c|c|c|c|c|c|c|}
\hline & Espécies & $\mathrm{F}$ & FR & $\mathrm{D}$ & DR & A & AR & IVI \\
\hline \multirow{3}{*}{$\mathrm{T} 1$} & C. hirta & 0.50 & 33.33 & 11.11 & 30.77 & 2.00 & 35.29 & 99.40 \\
\hline & P. niruri & 0.25 & 16.67 & 2.78 & 7.69 & 1.00 & 17.65 & 42.01 \\
\hline & S. oleraceus & 0.75 & 50.00 & 22.22 & 61.54 & 2.67 & 47.06 & 158.60 \\
\hline \multirow{3}{*}{$\mathrm{T} 2$} & C.hirta & 0.50 & 33.33 & 19.44 & 43.75 & 3.50 & 35.00 & 112.08 \\
\hline & S. oleraceus & 0.50 & 33.33 & 13.89 & 31.25 & 2.50 & 25.00 & 89.58 \\
\hline & outras & 0.50 & 33.33 & 11.11 & 25.00 & 4.00 & 40.00 & 98.33 \\
\hline \multirow{3}{*}{$\mathrm{T} 3$} & C. hirta & 0.50 & 50.00 & 5.56 & 33.33 & 1.00 & 20.00 & 103.33 \\
\hline & R.brasiliensis & 0.25 & 25.00 & 2.78 & 16.67 & 1.00 & 20.00 & 61.67 \\
\hline & S. oleraceus & 0.25 & 25.00 & 8.33 & 50.00 & 3.00 & 60.00 & 135.00 \\
\hline \multirow{2}{*}{$\mathrm{T} 4$} & S. oleraceus & 0.75 & 60.00 & 22.22 & 57.14 & 2.67 & 47.06 & 164.20 \\
\hline & R. brasiliensis & 0.50 & 40.00 & 16.67 & 42.86 & 3.00 & 52.94 & 135.80 \\
\hline \multirow{3}{*}{ T5 } & R. brasiliensis & 1.00 & 36.36 & 30.56 & 52.38 & 2.75 & 33.33 & 122.08 \\
\hline & S. oleraceus & 0.50 & 18.18 & 8.33 & 14.29 & 1.50 & 18.18 & 50.65 \\
\hline & outras & 1.25 & 45.45 & 19.44 & 33.33 & 4.00 & 48.48 & 127.27 \\
\hline \multirow{3}{*}{ T6 } & C. hirta & 0.50 & 40.00 & 19.44 & 58.33 & 3.50 & 41.18 & 139.51 \\
\hline & L.temulentum & 0.25 & 20.00 & 5.56 & 16.67 & 2.00 & 23.53 & 60.20 \\
\hline & outras & 0.50 & 40.00 & 8.33 & 25.00 & 3.00 & 35.29 & 100.29 \\
\hline \multirow[b]{3}{*}{$\mathrm{T} 7$} & R. brasiliensis & 0.75 & 37.50 & 25.00 & 60.00 & 3.00 & 47.37 & 144.87 \\
\hline & S.oleraceus & 0.75 & 37.50 & 11.11 & 26.67 & 1.33 & 21.05 & 85.22 \\
\hline & Commelina & 0.25 & 12.50 & 2.78 & 6.67 & 1.00 & 15.79 & 34.96 \\
\hline \multirow{3}{*}{$\mathrm{T} 8$} & A. conyzoides & 0.50 & 22.22 & 13.89 & 26.32 & 2.50 & 30.00 & 78.54 \\
\hline & R. brasiliensis & 0.75 & 33.33 & 19.44 & 36.84 & 2.33 & 28.00 & 98.18 \\
\hline & outras & 1.00 & 44.44 & 19.44 & 36.84 & 3.50 & 42.00 & 123.29 \\
\hline
\end{tabular}

F - Frequência; Fr - Frequência relativa; D - Densidade; Dr - Densidade relativa; A - Abundância; A - Abundância relativa; IVI - índice de valor de importância.

$\mathrm{T} 1=$ três linhas de couve com quiabeiro nas entrelinhas, $\mathrm{T} 2=$ três linhas de couve com quiabeiro a cada duas entrelinhas, T3 = três linhas de couve com quiabeiro adensado nas entrelinhas, $\mathrm{T} 4=$ três linhas de couve com quiabeiro adensado a cada duas entrelinhas, T5 $=$ couve em monocultivo, $\mathrm{T} 6$ = quiabeiro em monocultivo, $\mathrm{T} 7$ = quiabeiro em mono cultivo adensado e $\mathrm{T} 8=$ palhada de aveia.

Fonte: Autores. 
A espécie $S$. oleraceus, aos 152 DAT, predominou na área cultivada com couve-folha e quiabeiro adensado a cada 2 entrelinha (T4) e correspondeu a 57,14\% da densidade total de plantas daninhas. Nestas parcelas, observou-se a ocorrência de apenas as espécies $S$. oleraceus e R. brasiliensis. Por outro lado, nos cultivos solteiros de couve-folha (T5) e quiabeiro (T6), observou-se maior variedade de espécies de plantas daninhas.

A espécie $R$. brasiliensis apresentou maior IVI na área cultivada com quiabeiro solteiro adensado (T7), sendo responsável por $60 \%$ do total da densidade de plantas daninhas na parcela, seguida pela espécie S. oleraceus, que representou 26,67\% da densidade total e Commelina, que representou 6,67\% da densidade total das espécies nas parcelas.

Importante considerar que a baixa representatividade em quantitativos de algumas espécies não implica em menor nível de importância na área de cultivo, pois podem vir a ter maior relevância em cultivos posteriores, principalmente se não controladas de forma adequada (Costa et al., 2019).

Os resultados obtidos quanto ao conhecimento das espécies de plantas daninhas mais importantes podem auxiliar no manejo das espécies de plantas daninhas na área, pois o produtor pode evitar a dispersão de espécies mais agressivas e controlá-las de modo mais eficaz. As espécies Sonchus oleraceus e Richardia brasiliensis, identificadas com recorrência neste experimento nos sistemas de manejo avaliados, devem ser priorizadas no planejamento das estratégias de controle.

Dentre as limitações encontradas podemos destacar a ausência de controle dos fatores climáticos, que podem influenciar na dinâmica da comunidade infestante. As mudanças de clima, sazonalidade, tornam o experimento apropriado para a região em que foi realizada, no entanto em outras localidades, com diferentes condições climáticas, os resultados podem ser diferentes.

Para trabalhos futuros, torna-se importante explorar condição de manejo similar em outras regiões, ou até mesmo na mesma região em diferentes épocas. Ainda, pode-se avaliar o acúmulo de massa seca das plantas daninhas da comunidade infestante, com o objetivo de implementar os resultados obtidos.

\section{Conclusão}

O consórcio da cultura de couve-folha com a cultura do quiabeiro favorece a redução no número de plantas e na densidade de plantas daninhas por $\mathrm{m}^{2}$ ao final do ciclo de cultivo, se comparado apenas ao monocultivo da couve-folha.

As espécies com maior valor de importância ao final do ciclo na área de cultivo foram Sonchus oleraceus e Richardia brasiliensis e devem ser priorizadas na implementação de medidas de manejo.

\section{Agradecimentos}

A Fundação Araucária pela bolsa concedida.

\section{Referências}

Adekiya, A. O., Agbede, T. M., Aboyeji, C. M., Dunsin, O., \& Ugbe, J. O. (2017). Green manures and NPK fertilizer effects on soil properties, growth, yield, mineral and vitamin C composition of okra (Abelmoschus esculentus (L.) Moench). Journal of the Saudi Society of Agricultural Sciences, 18 (2), $218-223$.

Albuquerque, J. A. A., Sediyama, T., Silva, A. A., Alves, J. M. A., Finoto, E. L., Neto, F. A., \& Silva, G. R. (2012). Desenvolvimento da cultura de mandioca sob interferência de plantas daninhas. Planta Daninha, 30 (1), 37-45.

Almeida, U. O., Andrade Neto, R. C., Lunz, A. M. P., Tavella, L. B., Marinho, T. S., \& Nogueira, S. R. (2018). Ocorrência de plantas daninhas em cultivo de bananeira comprida em diferentes espaçamentos no Estado do Acre. South American Journal of Basic Education, Technical and Technological, 5 (1), 188203.

Almeida, U. O., Andrade Neto, R. C., Marinho, J. T. S., Gomes, R. R., Oliveira, J. R., Santos, R. S., Teixeira Júnior, D. L., \& Araújo, J. C. (2019). Fitossociologia de plantas daninhas em cultivo de açaizeiro. Revista Brasileira de Agropecuária Sustentável, 9 (3), $59-67$.

Alves, T. N., Echer, M. M., Sackser, G. A. B., Black, A. V., Klosowski, E. S., \& Macedo Junior, E. K. M. (2020). Desempenho produtivo da couve (Brassica oleracea L. var. acephala) consorciada com quiabeiro sob manejo orgânico. Research, Society and Development, 9 (12), 1-20. 
Araújo Júnior, B. B., Silva, P. S. L., Oliveira, O. F., \& Espinola Sobrinho, J. (2012). Controle de plantas daninhas na cultura do milho com gliricídia em consorciação. Planta Daninha, 30 (4), 767-774.

Arif, M., Cheema, Z. A., Khaliq, A., \& Hassan, A. (2015). Organic Weed Management in Wheat through Allelopathy. International journal of agriculture \& biology, 17 (1), 127-134.

Barbosa, J. A., Ferreira, S. D., Salvalaggio, A. C., Costa, N. V., \& Echer, M. M. (2018). Allelopathy of aqueous Pachyrhizus erosus L. extracts on Euphorbia heterophylla and Bidens pilosa. Pesquisa Agropecuária Tropical, 48 (1), 59-65.

Bernardes, V. A. P., Poletto, R. S., \& Alves, V. S. (2020). Aspectos do potencial alelopático do extrato aquoso das folhas de Mimosa ramosíssima Benth, na germinação e crescimento inicial de Panicum maximum cv. aruana e Amaranthus retroflexus L. Research, Society and Development, 9 (9), 1-13.

Canuto, R. S. O., Canuto, D. M. F., Oliveira, L. S., Jacobi, N. M. N. S., \& Ribeiro Neto, J. C. (2020). Levantamento fitossociológico de plantas daninhas em área de produção de café catuaí amarelo. Revista Inova Ciência \& Tecnologia, 6 (1), 18-23.

Cardoso, M. O., Antônio, I. C., Berni, R. F., \& Kano, C. (2017). Consórcio couve-de-folha (Brassica oleracea var. acephala) e cariru (Talinum triangulare) sob duas alternativas de fertilização em cultivo protegido. Horticultura Argentina, 36 (91), 96-109.

Costa, N. V., Rodrigues-Costa, A. C. P., Coelho, E. M. P., Ferreira, S. D., \& Barbosa, J. A. (2018). Métodos de controle de plantas daninhas em sistemas orgânicos: breve revisão. Revista Brasileira de Herbicidas, 17 (1), 25-44.

Costa, R. N., Ribeiro Silva, D. M., Rocha, A. O., Silva Lima, A. N., Camilo dos Santos, J. C. C., Santos Silva, L. K., \& Acchile, S. (2019). Levantamento fitossociológico de plantas daninhas em área de produção de mamão. Revista Científica Rural, 21 (3), 183-193.

Custódio, I. G., Karam, D., \& Borges, I. D. (2019). Levantamento fitossociológico de plantas daninhas na cultura do sorgo granífero em função do manejo químico. Revista Brasileira de Milho e Sorgo, 18 (1), 148-157.

D’amico-Damião, V., Barroso, A. A. M., Alves, P. L. C., \& Lemos, L. B. (2020). Intercropping maize and succession crops alters the weed community in common bean under no-tillage. Pesquisa Agropecuária Tropical, 50 (s/n) 1-10.

Fank-De-Carvalho, S. M., Marchioretto, M. S., \& Báo, S. N. (2010). Anatomia foliar, morfologia e aspectos ecológicos das espécies da família Amaranthaceae da Reserva Particular do Patrimônio Natural Cara Preta, em Alto Paraíso, GO, Brasil. Biota Neotropica, 10 (4), 77-86.

Fukushi Y. K. M., Junqueira, A. M. R., Sugasti, J. B., \& Saboya, P. (2011). Consórcio de alface, quiabeiro e rabanete e efeito sobre a infestação de plantas espontâneas. Horticultura Brasileira, 29 (2), 2343-2350.

Gazziero, D. L. P., Lollato, R. P., Brighenti, A. M., Pitelli, R. A., \& Voll, E. (2015). Manual de identificação de plantas daninhas da cultura da soja. (2 ${ }^{\mathrm{a}}$.ed.) Londrina: Embrapa Soja.

Hereford, J., Schmitt, J., \& Ackerly, D. D. (2017). The seasonal climate niche predicts phenology and distribution of an ephemeral annual plant, Mollugo verticillata. Journal of Ecology, 105, 1323-1334.

Koefender, J., Schoffel, A., Manfio, C. E., Golle, D. P., Silva, A. N., \& Horn, R. C. (2016). Consorciação entre alface e cebola em diferentes espaçamentos. Horticultura Brasileira, 34 (4), 580-583

Lorenzi, H. (2008). Plantas daninhas do Brasil: terrestres, aquáticas, parasíticas e tóxicas: Instituto Plantarum.

Lorenzi, H. (2008). Plantas medicinais no Brasil: nativas e exóticas. Instituto Plantarum.

Machado, V. D., Tuffi Santos, L. D., Santos Junior, A., Mota, V. A., Padilha, S. V., \& Santos, M. V. (2011). Fitossociologia de plantas daninhas em sistemas de Integração de sorgo com braquiária sob diferentes formas de Implantação da pastagem. Planta Daninha, 29 (1), 85-95.

Maciel, C. D. G., Poletine, J. P., Oliveira Neto, A. M., Guerra, N., \& Justiniano, W. (2010). Levantamento fitossociológico de plantas daninhas em cafezal orgânico. Bragantia, 69 (3), 631-636.

Mahgoub, A. M. M. A. (2019). The impact of five environmental factors on species distribution and weed community structure in the coastal farmland and adjacent territories in the northwest delta region. Heliyon, 5 (4), 1-33.

Marques, L. J. P., Silva, M. R. M., Lopes, G. S., Corrêa, M. J. P., Araújo, M. S., Costa, E. A., \& Muniz, F. H. (2011). Dinâmica de populações e fitossociologia de plantas daninhas no cultivo do feijão-caupi e mandioca no sistema corte e queima com o uso de arado. Planta Daninha, 29 (spe), 981-989.

Meirong, L. (1993). Leaf photosynthetic nitrogen use efficiency of C3 and C4 Cyperus species. Photosynthetica, 29 (1), 117-130.

Moreira, G. M., Oliveira, R. M., Barrela, T. P., Fontanétti, A., Santos, R. H. S., \& Ferreira, F. A. (2013). Fitossociologia de plantas daninhas do cafezal consorciado com leguminosas. Planta Daninha, 31 (2), 329-340.

Moura Filho, E. R., Macedo, L. P. M., \& Silva, A. R. S. (2015). Levantamento fitossociológico de plantas daninhas em cultivo de bananeira irrigada. Holos, 2 (31), 92-97.

Mueller-Dombois, D., \& Ellenberg, H. (1974). Aims and methods of vegetation ecology: John Wiley \& Sons.

Oliveira, A. C. S., Coelho, F. C., Crevelari, J. A., Fernandes da Silva, I., \& Rubim, R. F. (2014). Fitossociologia de plantas daninhas em monocultivo de milho e em consórcio com diferentes Fabaceae. Revista Ceres, 61 (5), 643-651.

Oliveira, A. R., \& Freitas, S. P. (2008). Levantamento fitossociológico de plantas daninhas em áreas de produção de cana-de-açúcar. Planta Daninha, 26 (1), 33-46. 
Olsen, J. M., Griepentrog, H., Nielsen, J., \& Weiner, J. (2012). How important are crop spatial pattern and density for weed suppression by spring wheat? Weed Science, 60 (3) 501-509.

Paula, F. N., Mata, J. F., Fujita, A. T., Martins, H. L., \& Paula, P. R. F. (2020). Potencial alelopático de bioextratos dos resíduos da cana-de-açúcar no controle de Bidens pilosa e Taraxacum officinale. Revista de la Facultad de Agronomía, 119 (1), 1-11.

Pitelli, R. A. (2000). Estudos fitossociológicos em comunidades infestantes de agroecossistemas. J. Consherb, 1 (2), 1-7.

Rezende, B. A., Barros Junior, A. P., Cecílio Filho, A. B., Porto, D. R. Q., \& Martins, M. I. E. G. (2009). Custo de produção e rentabilidade das culturas de alface, rabanete, rúcula e repolho em cultivo solteiro e consorciadas com pimentão. Ciência e Agrotecnologia, 33 (1), 305-312.

Rosa, D. M., Nóbrega, L. H. P., Mauli, M. M., \& Lima, G. P. (2011) Comportamento da comunidade invasora na cultura do milho consorciado com leguminosas. Varia Scientia Agrárias, 2 (2), 99-106.

Santos, H. G., Jacomine, P. K. T., Anjos, L. H. C., Oliveira, V. A., Lumbreras, J. F., Coelho, M. R., Almeida, J. A., Araújo Filho, J. C., Oliveira, J. B., \& Cunha, T. J. F. (2018). Sistema brasileiro de classificação de solos. (5a ed.) rev. e ampl: Embrapa.

Santos, R. N. V., Pires, T. P., Mesquita, M. L. R., Correa, M. J. P., \& Silva, M. R. M. (2020). Weed interference in okra crop in the organic system during the dry season. Planta Daninha, $38(\mathrm{~s} / \mathrm{n}), 1-10$.

Santos, J. B., Silveira, T. P., Coelho, P. S., Costa, O. G., Matta, P. M., Silva, M. B., \& Drumond Neto, A. P. (2010). Interferência de plantas daninhas na cultura do quiabeiro. Planta Daninha, 28 (2), 255-262.

Smith, A. E. (1989). The potential allelopathic characteristics of bitter sneezeweed (Helenium amarum). Weed Science, 37 (5), 665-669.

Trani, P. E., Camargo, M. S., Foltran, D. E., Hiroce, R., Arruda, F. B., \& Sawasaki, H. E. (2008). Produtividade e pseudoperfilhamento do alho influenciados pelo nitrogênio, potássio e cobertura morta. Horticultura Brasileira, 26 (3), 330-334.

Uljol, L. H. O., Bianco, S., Filho, A. B. C., \& Carvalho, L. B. (2018). Weed interference on productivity of bell pepper crops. Planta Daninha, 36 (s/n), 1-12.

Ziech, A. R. D., Conceição, P. C., Luchese, A. V., Balin, N. M., Candiotto, G., \& Garmus, T. G. (2015). Proteção do solo por plantas de cobertura de ciclo hibernal na região Sul do Brasil. Pesquisa agropecuária brasileira, 50 (5), 374-382. 